Преводна статия от Европейското списание по болнична фармация, публикувана с разрешение на Европейската асоциачия на болничните фармаџевти (ЕАНР)

The original source of this article is: HPA Scheepers, AM Beaney, PPH Le Brun, $V$ Neerup Handlos, MDB Schutjens, $S$ Walser and $C$ Neef. Aseptic preparation of parenteral medicinal products in healthcare establishments in Europe. Eur J Hosp Pharm 2016 23: 50-53

doi: 10.1136/ejhpharm-2015-000709

\title{
ASEPTIC PREPARATION OF PARENTERAL MEDICINAL PRODUCTS IN HEALTHCARE ESTABLISHMENTS IN EUROPE
}

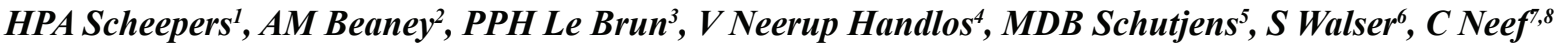 \\ ${ }^{I}$ Department of Health Care Inspectorate, Ministry of Health, Welfare and Sport, Utrecht, The Netherlands \\ ${ }^{2}$ Regional Quality Assurance Specialist, Royal Victoria Infirmary, Newcastle upon Tyne, UK \\ ${ }^{3}$ Apotheek Haagse Ziekenhuizen, The Hague, The Netherlands \\ ${ }^{4}$ Capital Region Pharmacy, Herlev, Denmark \\ ${ }^{5}$ Department of Pharmaceutical Law, University of Utrecht, Utrecht, The Netherlands \\ ${ }^{6}$ European Directorate for the Quality of Medicines \& HealthCare (EDQM), Council of Europe, Strasbourg, \\ France \\ ${ }^{7}$ Department of Clinical Pharmacy, Maastricht University Medical Centre, Maastricht, The Netherlands \\ ${ }^{8}$ CAPHRI School for Public Health and Primary Care, Maastricht, The Netherlands
}

\section{АСЕПТИЧНО ПРИГОТВЯНЕ НА ПАРЕНТЕРАЛНИ ЛЕКАРСТВЕНИ ПРОДУКТИ В ЛЕЧЕБНИ ЗАВЕДЕНИЯ В ЕВРОПА}

\author{
ХПА Шийпърс 1 , АМ Бийни ${ }^{2}$ ППХ Ле Брун ${ }^{3}$, В Нийруп Хандолс ${ }^{4}$, МДБ Шутиенс ${ }^{5}$, С Валсер ${ }^{6}$, \\ К Нийф ${ }^{7,8}$ \\ ${ }^{1}$ Инспекторат на Министерството на здравеопазването, Министерство на Здравеопазването, \\ благосъстоянието и спорта, Утрехт, Нидерландия \\ ${ }^{2}$ Специалист Регионално осигуряване на качеството, Лечебнииа Роял Виктори, Нюкасъл на Тайн, \\ Великобритания \\ ${ }^{3}$ Аптека Хаагсе Цинкенхойцен, Хага, Нидерландия \\ ${ }^{4}$ Аптека столичен регион, Харлев, Дания \\ ${ }_{5}^{5}$ Катедра по Фармачевтично право, Университет на Утрехт, Утрехт, Нидерландия \\ ${ }^{6}$ Европейската дирекиия по качество на лекарствата \& здравеопазването (EDQM), Съвет на Европа, \\ Страсбург, Франиия \\ ${ }^{7}$ Катедра по клинична фармация, Университетски медицински център Маастрихт, Маастрихт, \\ Нидерландия \\ ${ }^{8}$ CAPHRI училище за обществено здраве и първичната медииинска помощ, Маастрихт, Нидерландия
}

Резюме. Парентералните лекарствени продукти с разрешение за употреба не могат да се дават непосредствено на пациентите, т. е. те не са във фрорма, готова за употреба. Преди да се приложат на пациентите, тези лекарства трябва да се реконституират. Реконституираната форма не се счита нито за фрабрично произведен, нито „стандартен“ продукт приготвен в аптека. Има други процеси в здравните заведения, свързани с процеса на реконституиране (напр. парентералното хранене), за които националните изисквания на стандартите за осигуряване на качеството за безопасно приготвяне на стерилни продукти са също толкова важни и задължителни. В европейските здравни заведения асептично- 
то приготвяне на парентерални лекарствени продукти се счита за процес с изключителна важност за безопасността на пациентите, поради това, че грешки при приготвянето на тези лекарства може да доведат до получаване на продукт, който да причини непосредствена вреда на пациента. Асептичното приготвяне на лекарствени продукти се извършва както в болничните аптеки, така и в клиничните зони в лечебните заведения. Комисията от експерти в областта на стандартите за качество и безопасност за фармацевтични практики и фрармацевтични грижи (Съвета на Европа, наричана за краткост Експертна комисия), със съдействието на Европейската дирекция по качеството на лекарствата и здравеопазването извършва действия в областта на асептичното приготвяне на лекарства. Работи се съвместно с Европейската асоциация на болничните фрармацевти на основание Резолюция CM/Res AP(2011)1 за изискванията за гарантиране на качество и безопасност за лекарствените продукти, приготвени в аптеки за специални нужди на пациентите, приета от Комитета на министрите на 19 януари 2011 г. Резолюцията съдържа някои препоръки и излага перспективата за по-нататъшна работа в областта на реконституирането на парентерални лекарства. Проучване, изпратено до различни европейски страни, показва, че или отсъства регламентиране на реконституирането в Европа, или ако съществува, то е много ограничено. Настоящата статия разглежда рисковете, свързани с лоши практики на реконституиране и извършените и настоящите дейности в областта на европейско ниво. Статията подчертава необходимостта от регламентиране по темата, каквото в момента липсва. Очаква се да се постигне консенсус по документ с указания за реконституиране на европейско ниво.

Abstract. In many cases, parenteral medicines with a marketing authorisation cannot be administered directly to patients, that is, they are not presented in ready-to-administer form. Before administration to patients, these medicines have to be reconstituted. Reconstitution has a special position; it can neither be seen as industrial manufacture nor as 'regular' pharmacy preparation. There are other processes in healthcare establishments (eg, parenteral nutrition), related to the reconstitution process, where the requirements of national quality assurance standards for the safe preparation of sterile products are equally important and have to be fulfilled. In European healthcare establishments, aseptic preparation of parenteral medicinal products is considered to be a process of crucial importance for patient safety because errors in the preparation of these medicines may lead to a product that can cause immediate damage to patients. Aseptic preparation of medicinal products is carried out in hospital pharmacies as well as in clinical areas in healthcare establishments. The Committee of Experts on Quality and Safety Standards for Pharmaceutical Practices and Pharmaceutical Care (Council of Europe; hereafter: Committee of Experts), supported by the European Directorate for the Quality of Medicines \& Healthcare, is undertaking work on the topic of aseptic preparation of medicines. The work is carried out in cooperation with the European Association of Hospital Pharmacists on the basis of a Resolution CM/Res AP(2011)1 on Quality and Safety Assurance requirements for Medicinal Products prepared in Pharmacies for the Special Needs of Patients, which was adopted by the Committee of Ministers on 19 January 2011. The Resolution includes some recommendations and an outlook to further work on reconstitution of parenteral medicines. A survey that was sent to the different European countries demonstrated that there is no or just limited regulation concerning reconstitution in Europe. This article describes the risks associated with poor reconstitution practices and the previous work as well as the ongoing activities concerning reconstitution at the European level. The article emphasises the need for regulation in this area, which is missing at present. It is expected that consensus can be reached on a guidance document for reconstitution at the European level. 


\section{ВЪВЕДЕНИЕ}

В много случаи парентерални лекарствени продукти с разрешение за употреба не могат да бъдат прилагани пряко на пациентите, поради факта, че не са във форма, готова за употреба. Преди да се дадат на пациентите, тези продукти трябва да се реконституират. Болничните аптеки могат да осигуряват парентерални продукти, готови за употреба. Процесът на реконституиране, предхождащ въвеждането на продукта, може да варира от просто приготвяне до многобройни или много сложни операции.

Реконституирането се отнася до лекарствени продукти с разрешение за употреба, които все още не са готови да бъдат използвани от пациентите и може да се извършва в различни сектори на здравното заведение. Има и други дейности в здравните заведения (например парентералното хранене (ПХ)), свързани с процеса на реконституиране, за които националните изисквания на стандартите за осигуряване на качеството за безопасно приготвяне на стерилни продукти са също толкова важни и задължителни. Асептичното приготвяне на парентерални лекарствени продукти в здравните заведения е свързано с рискове за безопасността на пациентите. Адекватното реконституиране на лекарствени продукти се определя от страна на националните органи, здравните заведения и болничните фармацевти като решаващо за безопасността на пациентите. Реконституирането се дефинира като манипулация, чрез която се позволява въвеждането на лекарствен продукт с разрешение за употреба съгласно указанията, посочени в кратката характеристика на продукта (КХП) или в листовката за пациента. Това определение за реконституиране е въз основа на консенсус, постигнат сред 36 страни-членки на Съвета на Европа (1). От регулаторна гледна точка, реконституирането има особен статут:

1. Реконституирането не може да се счита за част от процеса на фабрично производство, защото се извършва извън условията на индустриално изготвяне. Регламентирането на лекарствените продукти, произведени в индустриални условия, е ясно и е предмет на международно внимание; производителят е длъжен да спазва Добрите производствени практики 2 на ЕС, като се изисква разрешение за употреба на продуктите, издадено от съответния компетентен регулаторен орган, преди продуктите да излязат на пазара.
2. Реконституирането не може да се счита за „стандартен“ приготвен в аптека продукт, защото изходният материал за реконституирането е лекарствен продукт с разрешение за употреба, вместо активна фармацевтична съставка и защото реконституирането често се извършва в клинични условия, а не в аптеки. Приготвянето на лекарствени продукти (ЛП) в аптеки е от компетентността на националното регламентиране и не е предмет на международна уредба.

3. Предвид специалния статут на реконституирането, в Резолюцията за фармацевтичните препарати е отделен специална разпоредба (член 9) (1).

В настоящата статия разглеждаме реконституирането на парентерални лекарствени продукти (ПЛП). Инициирана е работна група за разработването на указания за безопасно реконституиране. В този материал първо ще изложим рисковете при реконституирането, след което ще представим начини за подобряване на процеса и ролята на оценката на риска.

\section{РИСКОВЕ, СЫЩЕСТВУВАЩИ ПРИ РЕКОНСТИТУИРА- HETO}

Рискове за пациентите поради лоши практики на реконституиране

Приготвянето на ПЛП в здравни заведения в клинични условия, като например отделения или операционни зали е процес, свързан с високи рискове от микробиологично замърсяване, неправилен състав на продукта и проблеми за здравето и безопасността (3-7). Установена е зависимост между грешките и допълнителната заболеваемост и смъртност в групи лица, които вече са тежко болни (8). Грешките, свързани с ПЛП представляват сериозен проблем за безопасността и се определят като високо приоритетна тема в лечебните заведения (9-11). Поради това реконституирането е от ключово значение за безопасността на пациентите (12-18).

Видове рискове, свързани с лоши практики за реконституиране

Реконституирането на ПЛП може да носи следните рискове:

- Възможни проблеми в процеса на реконституиране.

Грешки в процеса на реконституиране на ПЛП, могат да доведат до администрирането на неадекватно лекарство на пациента (19). 
По-долу са дадени някои примерни грешки:

- реконституиране на грешно лекарство (15)

- реконституиране на грешна доза (15)

- реконституиране на лекарство за грешен път на въвеждане (15)

- Грешки при изчисленията, водещи до администриране на грешна доза и/или грешна концентрация или честота (17)

- Погрешно реконституиране (недостатьчно смесване, непълно разтваряне, използване на погрешен разтворител) (18)

- Съдържание на етикет (17)

- Лоши асептични техники (вж. по-късно) (18)

- Пропуск да се извърши двоен контрол от независимо второ лице (16)

- Неспазване на указанията за реконституиране, посочени от производителя в КХП (16)

- Използване на ЛП, разтворител или инфузионен разтвор с изтекъл срок на годност (или съответно твърде дълго след приготвянето) (17)

- Несъвместимост между разтворител, инфузионен разтвор, друг ЛП или изделие за въвеждане (16)

- Процесът на реконституиране е неясно или непълно описан в КХП, което води до погрешно тълкуване (16).

- Риск от микробиологично замърсяване.

Много често реконституирането на ПЛП се извършва в клинични условия, например в отделения, операционни зали и клиники. В такива неконтролирани среди трудно се осигурява асептичност. Лоши практики с оглед на асептичността (техники без допир), водещи до замърсяване на продукта и вреда за пациента представляват риск. Поради това рискът от микробиологично замърсяване следва да се сведе до абсолютен минимум при реконституирането (20).

По данни в литературата асептичните процедури, свързани с процеса на реконституиране често са със слабости, (18) което крие риск лекарството да е микробиологично замърсено. Също така литературата сочи, че микробиологичното замърсяване на спринцовки при реконституиране, извършвано от сестри в интензивни отделения варира между 7\% и 44\% (20). В аптека с квалифициран персонал и контролирана среда обикновено тези нива са значително по-ниски (20). Документирани са смъртни случаи в следствие на интравенозна анестезия, замърсена с вируси или бактерии (21). Благоприятна за микроорганизми хранителна среда може да е фактор, причиняващ по-висока норма на усложнения заради инфекции (22). Отчетени са и смъртни случаи, свързани с ПХ (23-25).

\section{Необходимост от намаляване на рисковете за пациентите}

За целите на намаляване на рисковете за пациентите Комисията на експертите към Съвета на Европа разгледа възможността за разработване на допълнителни указания за процедурите по реконституиране, с координация от отстрана на Европейската дирекция по качеството на лекарствата и здравеопазването (ЕДКЛЗ, Съвет на Европа). Една от констатациите от проучване сред европейски държави, проведено от тази Експертна комисия, е че в областта на реконституирането регламентация или изобщо липсва, или ако има такава, тя е много ограничена.

\section{ПредХОДНА РАБОТА в Съвета НА ЕвРОПА}

Обща информация относно проекта в областта на реконституирането като надграждане на базата на предходни дейности

През 2008 г. работна група на Експертната комисия, председателствана от съответния автор и с участие на делегации от Австрия, Норвегия и Швейцария, изпрати проучване за стандартите за осигуряване на качество и безопасност за изготвянето на ЛП до различни държави, членуващи в Съвета на Европа. Фактьт, че регламентите за продукти, произведени от фармацевтичната индустрия и за препаратите, изготвени в аптеки не са единни, послужи като причина за изследването. Резултатите от него са публикувани (26). По-долу са представени основните изводи.

Приготвянето на лекарства в аптеки и реконституирането на парентерални лекарства е неоценимо с оглед индивидуалните нужди и медицинско състояние на пациентите както в Европа, така и извън пределите й. Приготвянето на ЛП в аптеки, в частност стандартите за осигуряване на качество и безопасност, не са хармонизирани в рамките на Европа и са от компетентността на отделните европейски държави. След приключването на горното изследване (26), проведено от Комисията от експерти в областта на стандартите за качество и безопасност за фармацевтични практики и фармацевтични грижи (Съвета на Европа), с подкрепата на ЕДКЛЗ, бяха установени големи различия между различните страни, участвали в проучването, във 
връзка с осигуряването и стандартите за качество за ЛП, приготвяни в аптеки, както и разминаване по отношение на осигуряването на качество при приготвянето на препарати в аптеки и продуктите, произвеждани от фармацевтичната индустрия. Изследването установи и отсъствие на регламентиране или силно ограничено регламентиране на реконституирането. Въз основа на тази работа (26) се проведе по-нататъшна дискусия сред професионалисти от 21 европейски страни на работни семинари (27). В резултат на това се излъчи Резолюция (1) за препаратите, приготвяни в аптеки, отразяваща някои от препоръките и перспективата за по-нататъшна работа в областта на реконституирането на парентерални лекарства.

\section{РЕЗОЛЮЦИЯ ЗА ХАРМОНИЗАЦИЯ НА ИЗГОТВЯНЕТО НА ПРЕПАРАТИ В АПТЕКИ СЪС СПЕЦИАЛНИ РАЗПО- РЕДБИ ЗА РЕКОНСТИТУИРАНЕТО}

През декември 2010 г. Експертната комисия предложи стандарти за хармонизиране на стандартите за приготвянето на ЛП в аптеки в Европа под формата на проекторезолюция с нарочна разпоредба (член 9) за реконституирането (1).

Комитетът на министрите е приел Резолюция CM/Res AP(2011)1 (1) за изискванията за осигуряване на качество и безопасност за ЛП, приготвени в аптеки за специалните нужди на пациентите, отново с разпоредба за реконституирането. Комитетът на министрите препоръчва на страните-членки да изменят своето законодателство за съответствие с изискванията на Резолюцията. Тя е декларация на политическа воля, но прилагането й не е правно обвързващо, за разлика например от директиви на EC, като страните-членки ще отчитат местната нормативна уредба.

Резолюцията (1) е важен пробив за предотвратяването на пропуски и разминаване във връзка с качеството и безопасността на ЛП, приготвени в аптеки и ЛП, произведени фабрично, чрез определяне на основни елементи на осигуряването на качество в процеса на приготвяне. Пациентьт има право да получава продукт, отговарящ на съответните стандарти за качество, независимо в какви условия е приготвен (фабрично, в аптека или в здравно заведение). Резолюцията съдържа новаторски подход, като подкрепа на процесите на взимане на решения за определяне на необходимото ниво стандарти за качество (1).
Въвеждането на стандарти, установени от Съвета на Европа за осигуряване на качество и безопасност на лекарства, приготвяни в аптеки, може да предотврати сериозни инциденти с такива лекарства в Европа. Такива сериозни инциденти са се случвали в други държави извън Европа, главно в САЩ (28-30).

\section{РАЗПОРЕДБИ ОТНОСНО РЕКОНСТИТУИРАНЕТО В РЕзолюцИЯтА}

В член 9 от Резолюцията (1) се визира специално реконституирането на ЛП в лечебни заведения. Разпоредбата гласи, че реконституирането на ЛП за предпочитане следва да се извършва в аптека, като се приема, че [там] може да бъдат изпълнени изискванията за безопасно приготвяне на продуктите.

Оценка на риска за реконституиране следва да помогне на здравното заведение при взимането на решения и документирането, свързано с това кои продукти трябва да се реконституират в аптеки и кои могат да се реконституират в клинични условия като отделения, операционни и клиники.

Според авторите на резюмето на доклада по проучването, реконституирането на ЛП с разрешение за употреба за приготвяне на ЛП, готов за прилагане, е сива зона (26), изискваща допълнителна работа. Резолюцията (1) препоръчва на националните власти да разработят, съвместно със съответните професионални организации, конкретна нормативна уредба или указания, с отчитане на факторите, посочени в член 9 на Резолюцията (1). В момента нормативната уредба на реконституирането на парентерални лекарства или отсъства, или е недостатъчна в повечето държави от Съвета на Европа.

\section{ДЕЙНОСТИ в СъвеТА НА ЕвРОПА, КОИТО СА В ХОД В ОБЛАСТТА НА РЕКОНСТИТУИРАНЕТО}

Решение да се работи в областта на реконституирането

Въз основа на предходно изследване, извършено от Експертната комисия в областта на лекарствата, приготвяни в аптеки, бяха подети инициативи в рамките на същия орган за работа в областта на реконституирането. Направено бе проектно предложение и се постигна консенсус сред страните-членки на Съвета на Европа за стартиране на проекта. Сред факторите, на които се обръща 
внимание, са различните условия, в които да се извършва реконституиране, подход, отчитащ риска, свързан с различните видове реконституиране, услугите, свързани с реконституиране, предоставяни от аптеки и други управленски въпроси.

\section{ВНИМАНИЕ ВЪРХУ ПРОЦЕДУРИТЕ ЗА РЕКОНСТИТУ- ИРАНЕ В РАЗЛИЧНИ УСЛОВИЯ НА ТЕРИТОРИЯТА НА ЗДРАВНИТЕ ЗАВЕДЕНИЯ}

На практика процедурата по реконституиране може да се извършва както в аптеки, така и в клинични условия. В идеалния случай качеството на лекарствата за пациента не следва да зависи от мястото, в което се извършва реконституирането. В някои страни са установени указания за реконституиране, например във Великобритания (31), но това е необходимо да стане факт в цяла Европа. Указанията следва да обхващат работните методи и процедури за реконституиране и администрирането на парентерални лекарства в частност $(6,32,33)$.

Резолюцията подчертава важността на структурните подобрения на процедурите по реконституиране с помощта на надлежно управление на рисковете

Във всеки едни от тези обекти (аптеки или клинични зони) в лечебното заведение профилът на риска може да е различен, в зависимост от ситуацията в обекта (сложност на процеса на реконституиране, обстановка, материална база и оборудване, персонал и квалифицираност, други условия) и в зависимост от броя оперативни стъпки на реконституирането.

Реконституирането е широко понятие за различни дейности и услуги. Рисковите характеристики на различните процеси на реконституиране могат да са много различни и поради това е целесъобразно да бъдат отчитани. Използването на един и същ термин води до имплицитно, но превратно внушение, че профильт на риска за всички тези различни дейности е еднакъв.

Оценяването на риска за реконституирането може да помогне на здравните заведения при взимането на решения и документирането във връзка с това кои продукти могат безопасно да се реконституират в клинични условия при спазването на надлежните мерки за намаляване на риска, като например обучение. Управлението на риска единствено постфактум, т. е. в отговор на случили се инциденти, не е адекватен подход. Считаме, че процесът на въвеждане на подобрения въз основа на случили се инциденти трябва да бъде заменен с превантивен и инициативен процес на структурно подобрение, въз основа на отчитане на риска. Нашето мнение е, че това е възможно единствено при наличието на решимост от страна на ръководството и служителите във всяко едно лечебно заведение. Процесът на реконституиране за парентерални продукти и администрирането им на пациенти в лечебни заведения следва да се основава върху цялостна и задълбочена оценка на риска и добро управление.

Експертната комисия излага някои варианти, които са важни с оглед утвърждаването на добри практики за реконституиране, като например:

Определяне на конкретно лице в лечебното заведение, с надлежната квалификация, което генерално да отговаря за процеса на реконституирането на парентерални продукти (напр. болничен фармацевт).

Преглед в рамките на лечебното заведение на различните дейности по реконституиране в отделните места на извършването им (аптека, клинични зони), с диференциране на рискове.

Оценка за здравното заведение като цяло за начините за управление на тези рискове.

Решение кои продукти следва да се приготвят в болничната аптека и кои могат да се приготвят в клинични условия.

Оценка на капацитета в болничната аптека да осигурява парентерални продукти, готови за употреба, за определяне на високорискови продукти и за подкрепа на образованието персонала в клиничните зони за безопасно реконституиране на лекарствени продукти.

Ангажиментът и решимостта от страна на ръководството в здравното заведение са залог за напредък в областта на реконституирането на ПЛП.

Внимание върху процеса на реконституиране, без обхващане на последната стъпка - администрирането на лекарството на пациента

Работата на експертната комисия е насочена върху самия процес на реконституиране. Последната фаза на боравенето с ЛП е администрирането им на пациента. Трябва да бъдат въведени процедури за независима проверка от втори служител. Тази независима проверка трябва да включва проверка на данните на пациента, предписаното лечение и лекарството, което следва да се администрира. Грешки, допуснати на последния етап, т. е. при даването на лекарството на пациента, е невъзможно 
да бъдат поправени по-късно. Поради това подобни грешки при администрирането на лекарството на пациента могат също да са с критичен ефект за неговата безопасност.

\section{Изводи}

Понастоящем законодателно уреждане и/или указания относно реконституирането на ПЛП или отсъства, или е твърде недостатъчно в повечето държави, членуващи в Съвета на Европа. Резолюцията (1) препоръчва националните власти да разработят, съвместно със съответните професионални организации, конкретни регламенти или указания. За улесняване на работата в страните-членки, Експертната комисия е поела инициативата за изготвяне на законодателство или указания на международно ниво. Работата на Експертната комисия описва и е насочена към различните рискове, свързани с процеса на реконституиране и има за цел предоставянето на практически съвети за управлението на тези дейности. Очаква се Експертната комисия да излъчи препорьки за създаването на регламенти за Добри практики за реконституиране. При гласуване сред страните-членки на Съвета на Европа е възможно препоръките да бъдат приети. Предвид факта, че нормативно уреждане или указания в областта на реконституирането изобщо липсват или са твърде ограничени, подобно регламентиране на ниво Съвет на Европа би било важна стьпка напред за укрепване на безопасността на пациентите в областта на асептичното приготвяне на ЛП в лечебните заведения.

\section{КОНКУРЕНТНИ ИНТЕРЕСИ - НЕ СА НАЛИЦЕ}

Удостоверяване на източници и вътрешна рецензия - не е възлагано; проведена е външна рецензия.

\section{ИЗПОЛЗВАНИ ИЗТОЧНИЦИ}

1. Resolution $\mathrm{CM} / \operatorname{Res} \mathrm{AP}(2011) 1$ on quality and safety assurance requirements for medicinal products prepared in pharmacies for the special needs of patients. Council of Europe.

2. EU GMP. Eudralex Volume 4 Good Manufacturing Practice. http://ec.europa.eu/ health/documents/eudralex/vol-4/index en.htm (accessed 2 Apr 2015).

3. Ter Huurne K, Hendrix MGR, Colen HBB, et al. Again question marks with complex preparation activities. Nurses and preparation protocol of syringes. (Opnieuw vraagtekens bij complexe bereidingshandelingen. Verpleegkundigen en spuitbereidingsprotocollen.) Pharm Weekbl 2002;137:13837.

4. McDowell SE, Mt-lsa S, Ashby D, et al. Where errors occur in the preparation and administration of intravenous medicines: a systematic review and Bayesian analysis. Qual Saf Health Care 2010;19:341-5.

5. Han PY, Coombes ID, Green B. Factors predictive of intravenous fluid administration errors in Australian surgical care wards. Qual Saf Health Care 2005;14:179-84.

6. Hertzel C, Sousa VD. The use of smart pumps for preventing medication errors. J Infus Nurs 2009;32:257-67.

7. Malashock CM, Shull SS, Gould DA. Effect of smart infusion pumps on medication errors related to infusion device programming. Hosp Pharm 2004;39:460-9.

8. Garrouste-Orgeas M, Timsit JF, Vesin A, et al. Selected medical errors in the intensive care unit: results of the IATROREF study: parts I and II. Am J Respir Crit Care Med 2010;181:134-42.

9. Calabrese AD, Erstad BL, Brandl K, et al. Medication administration errors in adult patients in the ICU. Intensive Care Med 2001;27:1592-8.

10. Rothschild JM, Keohane CA, Cook EF, et al. A controlled trial of smart infusion pumps to improve medication safety in critically ill patients.* Crit Care Med 2005;33:533-40. (*See also pg 679.)

11. Valentin A, Capuzzo M, Guidet B, et al. Errors in administration of parenteral drugs in intensive care units: multinational prospective study. BMJ 2009;338:b814.

12. Kohn LT, Corrigan JM, Donaldson MS, Committee on quality of health care in America, Institute of Medicine. To Err is Human: Building a Safer Health System. Washington: National Academy Press, 2000.

13. Cousins DH, Sabatier B, Begue D, et al. Medication errors in intravenous drug preparation and administration: a multicentre audit in the UK, Germany and France. Qual Saf Health Care 2005;14:190-5.

14. Wirtz V, Taxis K, Barber ND. An observational study of intravenous medication errors in the United Kingdom and in Germany. Pharm World Sci 2003;25:104-11.

15. Taxis K, Barber N. Incidence and severity of intravenous drug errors in a German hospital. Eur J Clin Pharmacol 2004;59:815-17.

16. Rothschild JM, Landrigan CP, Cronin JW, et al. The Critical Care Safety Study: the incidence and nature of adverse events and serious medical errors in intensive care. Crit Care Med 2005;33:1694-700.

17. Phillips J, Beam S, Brinker A. Retrospective analysis of mortalities associated with medication errors. Am J Health Syst Pharm 2001;58:1835-41.

18. Van den Bemt PMLA, Egberts TCG, De Jong-van den Berg LTW, et al. Drug related problems in hospitalised patients [thesis], adverse events and medication errors systematically classified. Drug related problems defined and classified. Groningen: Rijksuniversiteit Groningen; Pharmaceutisch Weekblad 2002;137:1540-3.

19. Roelofsen EE, et al. Safety on prescription: a protocol for improving parenteral medication preparation and administration by nurses on the ward. (Veiligheid op recept: een protocol voor veilig voor toediening gereed maken en toedienen van parenteralia door verpleegkundigen.) Pharm Weekbl., wetenschappelijk platform 2007:78-83. 
20. Van Grafhorst JP, Foudraine NA, Nooteboom F, et al. Clean appearances are deceptive. Preparing of syringes for continuous intravenous drug administration in the intensive care unit. (Schone schijn bedriegt. Bereiding van perfusorspuiten op de intensive care.) Pharm Weekbl 2001;136:732-7.

21. Bennett SN, McNeil MM, Bland LA, et al. Postoperative infections traced to contamination of an intravenous anaesthetic, propofol. N Engl J Med 1995;333:147-54.

22. Tallis GF, Ryan GM, Lambert SB, et al. Evidence of patient-to-patient transmission of hepatitis $\mathrm{C}$ virus through contaminated intravenous anaesthetic ampoules. J Viral Hepat 2003;10:234-9.

23. Seres D, Sacks GS, Pederssen CA, et al. Parenteral nutrition safe practices: results of the 2003 American Society for Parenteral and Enteral Nutrition survey. J Parenter Enteral Nutr 2006;30:259-65.

24. Report from GERPAC conference, 2013. http://www.gerpac. eu/spip.php?article957 (accessed 17 Oct 2014).

25. Deutsche Welle article 20.08.10. http://www.dw.de/ two-babies-dead-five-critical- from-bacteria-at-germanhospital/a-5933837 (accessed 17 Oct 2014).

26. Scheepers HPA, Busch G, Hofbauer E, et al. Abridged survey report on quality and safety assurance standards for the preparation of medicinal products in pharmacies. Pharmeuropa 2010;22.

27. "Promoting Standards for the Quality and Safety Assurance of Pharmacy-Prepared Medicinal Products for the Needs of Patients", (24 September 2009 at the European Directorate for the Quality of Medicines \& HealthCare (EDQM), Council of Europe, in Strasbourg). http://www.edqm.eu/en/qualityand-safety-standards-1244. html (accessed 17 Oct 2014).

28. CDC, Centers for Disease Control and Prevention, Multistate Outbreak. Multistate Outbreak of Fungal Infection Associated with Injection of Methylprednisolone Acetate Solution from a Single Compounding Pharmacy — United States, 2012.

29. US Food and Drug Administration (FDA). CDC and ADPH investigate outbreak at Alabama hospitals; products recalled. (29 March, 2011). http://www.fda.gov/Safety/ Recalls/ ucm249068.htm (accessed 17 Oct 2014).

30. Wolfson H. Investigators piecing together tainted IV puzzle after deaths in Alabama hospitals. The Birmingham News 2011. http://blog.al.com/spotnews/2011/04/ investigators_ piecing_together.html (accessed 17 Oct 2014).

31. National Patient Safety Agency. Patient Safety Alert: promoting safer use of injectable medicines 20 . http:// www.nrls.npsa.nhs.uk/resources? entryid45 $=59812 \& \mathrm{p}=3$ (accessed 17 Oct 2014).

32. Bates DW, Vanderveen T, Seger DL, et al. Variability in intravenous medication practices: implications for medication safety. Jt Comm J Qual Patient Saf 2005;26:203-10.

33. Eskew JA, Jacobi J, Buss W, et al. Using innovative technologies to set new safety standards for the infusion of intravenous medications. Hosp Pharm 2002;37:1179-89.

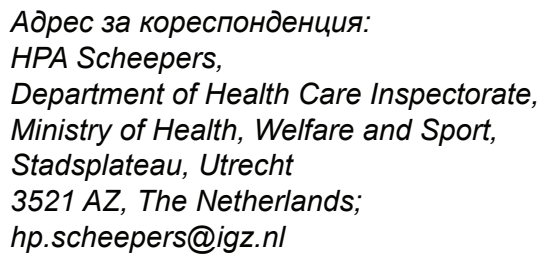

